\title{
Patient with Infiltrating Ductal Cell Carcinoma Mammae with Lung Tuberculosis and Nontuberculous Mycobacteria
}

\author{
Fitri Indah Sari $^{1}, \quad$ Yani Jane Sugiri ${ }^{1}$, Dwi Yuni Nurhidayati ${ }^{2}$ \\ ${ }^{1}$ Departement of Pulmonology and Respiratory Medicine Faculty of Medicine Brawijaya University, Dr. Saiful Anwar \\ Hospital, Malang \\ ${ }^{2}$ Departement of Microbiology Faculty of Medicine Brawijaya University, Dr. Saiful Anwar Hospital, Malang
}

\begin{abstract}
Introduction:. Infection caused by NTM has a prevalence which varies between 4.1 and 14.1 per 100,000 patients per year. Female has a higher prevalence of NTM disease than male, which is increasing with age, and more common in Western and Southeast Asian countries.

Case Description: A 42-year-old female patient has the clinical symptoms of hemoptysis, asphyxia, angina, fever, nocturnal hyperhidrosis, loss of weight and appetite for nearly 10 years. Based on the physical examination, radiology, microbiology and anatomic pathology, this patient has been diagnosed with Ca mammae with Pulmonary TB, and currently is infected by recurrent NTM.

Discussion: Symptoms of nonspecific NTM often complicate the diagnosis of TNM. General symptoms such as chronic cough, increased sputum production, dyspnea, fever that is not too high, weakness, weight loss so that it overlaps with other pulmonary symptoms. In NTM, radiological manifestations generally show bronchiectasis, nodular lesions, cavitary lesions and parenchymal consolidation. The choice of therapy in disease caused by NTM depends on three factors: the type of clinical presentation, the species of NTM causing the disease and the immune status of the patient.
\end{abstract}

Keywords: Ca Mammae, TBC, Recurrent NTM

MRJ 2021; 03(02):162-171

\section{Background}

NTM

(Nontuberculous

mycobacteria), or MOTT - which also known as "Mycobacterium Other Than Tuberculosis", $\quad$ "non-tuberculous mycobacteria", "mycobacteria other than M. tuberculosis", "opportunist mycobacteria", "unclassified mycobacteria", or "anonymous mycobacteria". ${ }^{1}$ It's also referred as environmental mycobacterium or atypical mycobacterium. ${ }^{2}$ The prevalence of lung infections caused by Nontuberculous Mycobacteria varies from 4.1 to 14.1 per 100,000 patients per year. ${ }^{3}$ In patients over 65 years old, the prevalence is around 47 per 100,000 patients per year. Women have a higher prevalence than men. The

${ }^{*}$ Corresponding author:

Fitri Indah Sari (fitrindahs1705@gmail.com)

Department of Pulmonology and Respiratory Medicine Medical Faculty of Brawijaya, Dr. Saiful Anwar Hospital, Malang 
prevalence also increases with age and are more commonly found in western and Southeast Asian countries. In the United States, the Caucasians account for $90 \%$ of cases followed by Asians (especially those from the Pacific Islands) and black people. ${ }^{4}$

NTM itself is widely spread throughout the environment, and basically stays in water and soil, as is the case with the Mycobacterium avium complex found in municipal waterworks, which can even go through tap water in hospitals, salt water, fresh fish, reservoir water and swimming pools. ${ }^{1}$ It has been identified that of more than 125 species of NTM, about 60 species are suspected and known to cause infection in humans. ${ }^{2}$ Diseases caused by NTM mainly occur in 3 (three) types of groups, i.e., the presence of pulmonary anatomical abnormalities with unidentified genetic basis; immunological or genetic disorders that predispose to bronchiectasis and / or lung infections; immunological abnormalities or lung disorders of unknown cause. ${ }^{5}$ Diagnosing lung disease due to NTM infection takes a long time, due to the slow growth of these bacteria, which often leads to the case being misdiagnosed with TB (Tuberculosis). ${ }^{6}$

The complexity and difficulty in diagnosing NTM of the lungs, thus, leads to this case report discussing about NTM in patients with breast cancer.

\section{Case Report}

A 42-year-old female patient female complained of coughing up blood for the last 9 years, bright red in color, with a volume of $\pm 1 / 4-1 / 2$ cup each, sometimes accompanied with a little white-colored sputum. The cough was recurring and did not relate to activity. The patient also complained of shortness of breath since 9 years ago, especially after coughing and doing activities. Orthopnea (+). Wheezing (+). PND (+). Shortness of breath felt alleviated in the last 1 month. The complaint of swollen feet was denied.

The patient complained of intermittent chest pain in the past 9 years, felt especially when doing activities. Pain is felt in the middle of the chest and then spreads to the back. Pain felt like she was being squeezed. The patient also complained of fever and sweat at night. Patients sometimes experienced nausea and vomiting. The patient experienced decreased appetite and weight loss.

In May 2008, the patient complained of a lump in the right breast and went to RSSA. FNAB was thus performed, and the result was declared malignant. In this patient, a surgical removal was performed on the breast tumor, with the biopsy result indicating Infiltrating Ductal Cell Carcinoma Mammae and continued with the first chemotherapy in June 2008. In December 2008 the patient coughed up 
blood and was examined for sputum with the results: AFB (+). She followed the management by taking category 1 antituberculosis drugs regimen for 6 months, followed by Rifampicin + Isoniazid for 3 months. In September 2009 the patient finished the TB treatment.

In December 2010, the patient complained of persistent cough and coughed up $\pm 1 / 4$ glass of bright red blood. Examination of sputum \& TCM: tuberculosis (+), chest X-ray showed bronchiectasis. The patient received category 2 antituberculosis drug regimen who finished treatment on August 8, 2011

On August 15t, 2011, the patient coughed up blood constantly and was hospitalized at Dr. Saiful Anwar Hospital for 15 days. Sputum examination was performed, and the result was NTM. She underwent NTM treatment: ethambutol 1 1/2 tab, Levofloxacin $1 \frac{1}{2}$ tab and Doxycycline $100 \mathrm{mg}$. Sputum culture was performed every 3 months for 18 months. Results: sometimes (+), sometimes (-). The last 2 tests were taken, and the results were: (-). In January 2013 the patient was cured. In July 2015, the patient was tested for sputum, the result showed NTM, and she was given 1 tab of Ethambutol, 1 tab of Levofloxacin, Rifampin 300 mg (3 months) was increased by $450 \mathrm{mg}$ (coughing up blood) \& Doxycycline $200 \mathrm{mg}$.
In February 2017, the patient coughed up blood $\pm 1 / 2$ liter / day and was hospitalized at Dr. Saiful Anwar Hospital for \pm 13 days, with the diagnosis: NTM, and underwent her 3rd NTM therapy, with drugs of choice: Azithromycin 1x250 mg, Etambutol 1 tab, Levofloxacin 1 tab, Rifampin $450 \mathrm{mg}$ for 5 months. The patient's sputum was cultured in LJ media, and the result was MTB, thus, she was diagnosed with $\mathrm{TB}$, given category 2 antituberculosis drug therapy without injection (performed together with chemotherapy).

The patient came to the ER on April $18^{\text {th }}, 2018$ with a stable hemodynamic condition, a blood pressure of 120/70 $\mathrm{mmHg}$, a pulse of $93 \mathrm{x} /$ minute, a respiratory rate of $18 x /$ minute, and an axillary temperature of $36.5^{\circ} \mathrm{C}$. The patient's weight was $35 \mathrm{~kg}$, the patient's height was $153 \mathrm{~cm}$, and the BMI was 14.95. In the coli region, there was an enlarged right submandibular lymph node $\pm 1 \mathrm{~cm}$ in diameter, solid, squishy, pain (-), venectation (-). In the thoracic region, there were 2 superolateral lumps in the left chest, diameter $\pm 0.5 \mathrm{~cm}$ and $1 \mathrm{~cm}$, not fixed, pain (-). The lung examination showed symmetrical respiratory movements, normal stem fremitus, normal percussion, normal breath sounds.

The patient underwent laboratory examination on July $19^{\text {th }}$, 2012, January 
$21^{\text {st }}, 2015$ and November $11^{\text {th }}, 2017$ prior to the diagnosis of NTM infection. The patient's laboratory examination on 2012 indicated leukocytopenia $(2,090 / \mu \mathrm{L})$ and thrombocytopenia $(117,000 / \mu \mathrm{L})$ which increased to normal $(6,510 / \mu \mathrm{L}$ and $289,000 / \mu \mathrm{L}$ respectively) on 2017 . The patient's examination also showed slight decrease of hematocrit valuing $35.6 \%$ in 2017. Her blood ureum examination had been normal in 2012 and 2015 (16.5 and $16.2 \mathrm{mg} / \mathrm{dL}$ ) and decreased to $0.6 \mathrm{mg} / \mathrm{dL}$ in 2017. The patient had normal total bilirubin $(0.81 \mathrm{mg} / \mathrm{dL})$ and indirect bilirubin $(0.46$ $\mathrm{mg} / \mathrm{dL}$ ) but a slightly increased direct bilirubin $(0.35 \mathrm{mg} / \mathrm{dL})$. Her SGOT/SGPT stayed normal throughout the years (less than $32 / 33 \mathrm{U} / \mathrm{L})$. Her laboratory result on 2017 also showed normal natrium (138 $\mathrm{mmol} / \mathrm{L}$ ) and increased kalium and chloride (3.29 and $108 \mathrm{~mol} / \mathrm{L}$ ), as well as increased uric acid (8.9).

Her laboratory examination on September $8^{\text {th }}$, 2018 indicated normal bilirubin T/D/I (0.24, 0.12 and $0.12 \mathrm{mg} / \mathrm{dL}$ respectively), normal SGOT/SGPT (12 and $4 \mathrm{U} / \mathrm{L})$, normal ureum $(18.2 \mathrm{mg} / \mathrm{dL})$ and increased creatinine level with the value of $0.74 \mathrm{mg} / \mathrm{dL}$ (normal: $<1.2 \mathrm{mg} / \mathrm{dL}$ ).

\section{Microbiology Examination}

\begin{tabular}{|c|c|c|c|c|c|}
\hline \multirow[b]{2}{*}{ Date } & \multicolumn{5}{|c|}{ Laboratory Examination Results } \\
\hline & AFB & $\begin{array}{l}\text { TCM MTB } \\
\text { Rif }\end{array}$ & Drug Sensitivity Test & Culture & $\begin{array}{l}\text { Molecular Test } \\
\text { (Real Time PCR) }\end{array}$ \\
\hline $2012 / 10 / 13$ & $\mathrm{Neg} / \mathrm{Neg} / \mathrm{Neg}$ & $\mathrm{x}$ & $\begin{array}{c}\text { Resistant: Isoniazid \& } \\
\text { Ethambutol } \\
\text { Sensitive: Rifampicin, } \\
\text { Streptomycin, Kanamycin, } \\
\text { Ofloxacin \& Amikacin }\end{array}$ & $\mathrm{x}$ & $\mathrm{x}$ \\
\hline $2013 / 2 / 12$ & $\mathrm{x}$ & $\mathrm{x}$ & $\mathrm{x}$ & NTM & $\mathrm{x}$ \\
\hline $2015 / 6 / 7$ & $\mathrm{x}$ & $\begin{array}{l}\text { MTB Not } \\
\text { Detected }\end{array}$ & $\mathrm{x}$ & $\mathrm{x}$ & $\mathrm{x}$ \\
\hline $2015 / 8 / 22$ & $\mathrm{x}$ & $\mathrm{x}$ & $\mathrm{x}$ & NTM & $\mathrm{x}$ \\
\hline $2016 / 11 / 3$ & AFB $1+$ & $\mathrm{x}$ & $\mathrm{x}$ & NTM & $\mathrm{x}$ \\
\hline $2017 / 2 / 3$ & $\mathrm{x}$ & $\begin{array}{l}\text { MTB Not } \\
\text { Detected }\end{array}$ & $\mathrm{x}$ & $\mathrm{x}$ & $\mathrm{x}$ \\
\hline $2017 / 2 / 6$ & $\mathrm{Neg} / \mathrm{Neg}$ & $\mathrm{x}$ & $\mathrm{x}$ & $\mathrm{x}$ & $\mathrm{x}$ \\
\hline $2017 / 7 / 14$ & $\mathrm{Neg} / \mathrm{Neg}$ & $\mathrm{x}$ & $\mathrm{x}$ & MTB & $\mathrm{x}$ \\
\hline $2017 / 10 / 3$ & $\mathrm{x}$ & $\begin{array}{l}\text { MTB Not } \\
\text { detected }\end{array}$ & $\mathrm{x}$ & MTB & $\mathrm{x}$ \\
\hline $2018 / 1 / 29$ & $\mathrm{Neg} / \mathrm{Neg}$ & $\mathrm{x}$ & $\mathrm{x}$ & $\mathrm{x}$ & $\mathrm{x}$ \\
\hline $2018 / 6 / 2$ & $\mathrm{x}$ & $\mathrm{x}$ & $\mathrm{x}$ & $\mathrm{x}$ & $\begin{array}{l}\text { Strong indication } \\
\text { of NTM Infection }\end{array}$ \\
\hline
\end{tabular}


Microbiology Examination (Figure 1) showed:
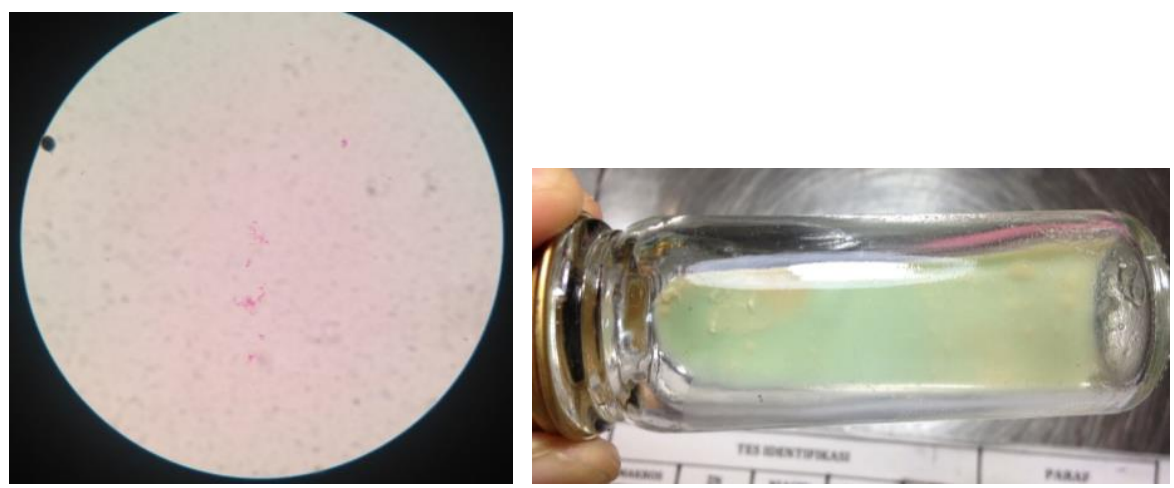

Figure 1. Acid Fast Mycobacterium Examination on May 6 ${ }^{\text {th }}, 2018$ (Left) and Non-Tuberculous Mycobacterium Culture on May 16 $6^{\text {th }}, 2018$ (Right)

Sputum cytology examination indicated class II, where no malignant cells were found. Epithelial cells with inflammatory changes and fungal infections, background inflammatory cells PMN, MN, histiocytes were found. Submandibular FNAB on 10 November 2017 indicated carcinoma metastases with mucinous carcinoma impressions

Radiology Examination (Figure 2, 3) showed:

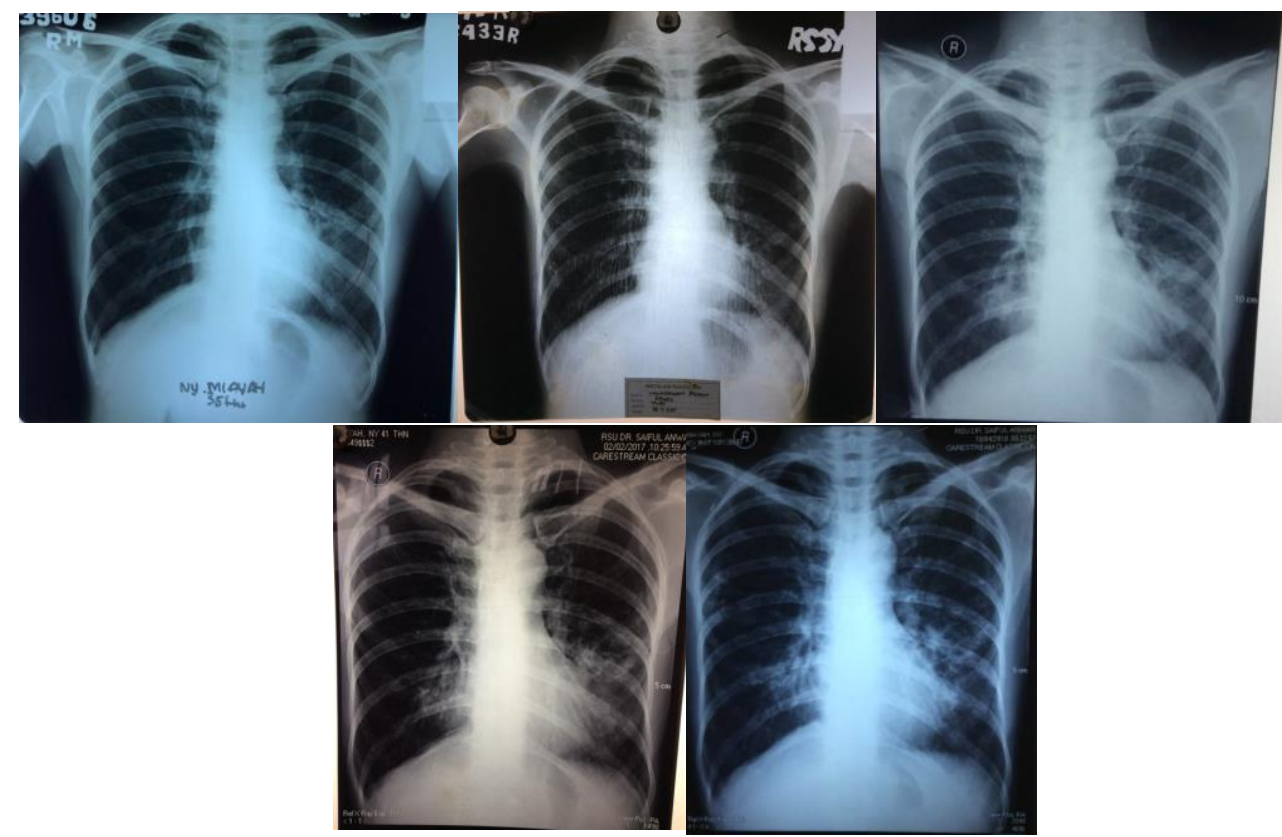

Figure 2. Chest Xray PA December $8^{\text {th }}, 2010$ - April 18 $8^{\text {th }}, 2018$ showed infected bronchyectasis and emphysematous lung 

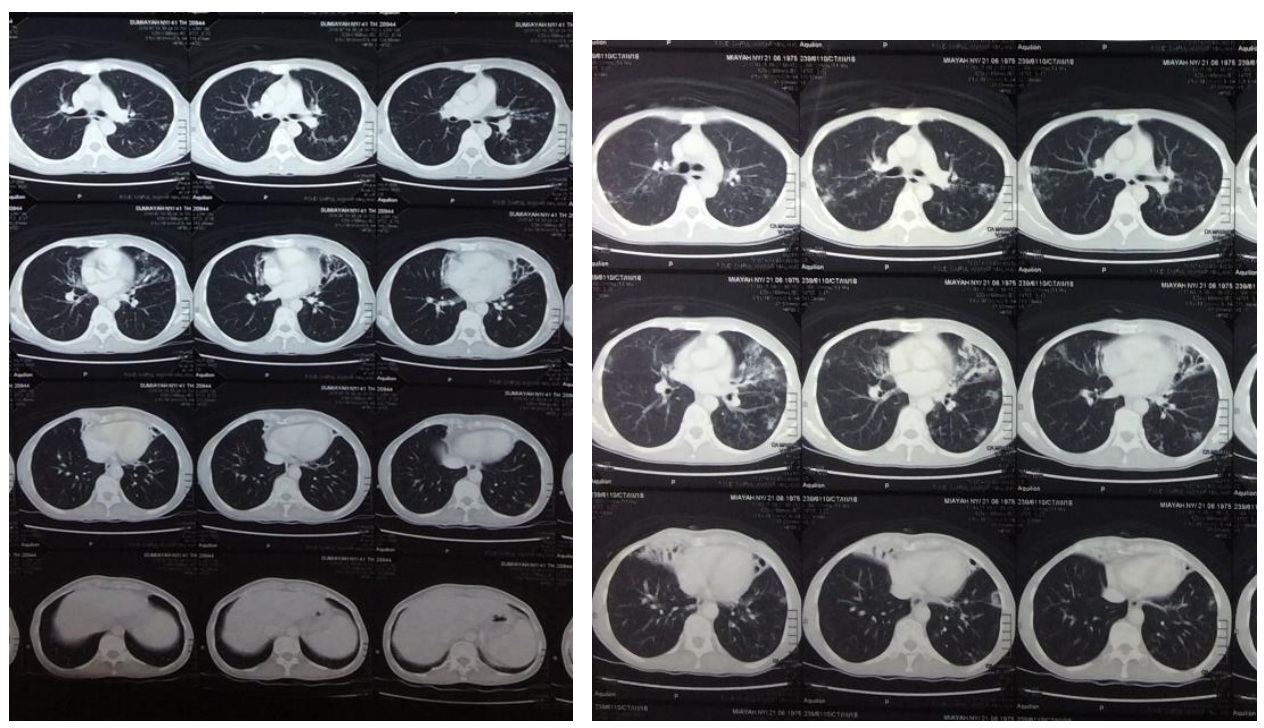

Figure 3. Thorax CT Scan on June 19 ${ }^{\text {th }}, 2016$ (Left) showed subsolid nodule on bilateral lung in accordance with metastatic process, cystic bronchiectasis on bilateral lung, left and right axilla lymph node, thoracal spondylitis. Thorax CT Scan on March $5^{\text {th }}, 2018$ (Right) showed multiple nodules on bilateral lungs, suspected metastatic process dd infection, with increased size and amount, infected cystic bronchiectasis on bilateral lung with cystic lesion relatively constant, and osteoporosis also relatively constant 
Mammography on March $30^{\text {th }}, 2016$ and April 18 ${ }^{\text {th }}, 2018$ showed a solid mass and a cystic mass on mammae sinistra BIRADS 3, accompanied by bilateral axilla lymphadenopathy, with suspicious characteristics.

\section{Discussion}

In this case, a 42-year-old female patient, working as a tailor and lived in a house with empty lands as the surrounding environment came with complaints of coughing up blood in the last 9 years, bright red in color, with a volume of $\pm 1 / 4-1 / 2$ cup per cough, sometimes accompanied by a little white-colored sputum. The cough was intermittent and not related to activity. The patient also complained of shortness of breath in the last 9 years, especially after coughing and activities, Wheezing and PND were found. The patient also complained of chest pain since 9 years ago, the pain came and go and especially felt after doing activities. The pain was felt in the middle of the chest and then spread to his back, and felt like she was being squeezed. The patient also complained of frequent fever, night sweats, decreased appetite and weight, but the patient did not know how many kgs she had lost. Women have a higher prevalence than men. The prevalence also increases with age and are more commonly found in western and Southeast Asian countries. ${ }^{4}$ Symptoms of NTM are not specific, i.e., as chronic cough, increased sputum production, dyspnea, fever that is not too high, weakness, weight loss, thus, overlaps with other pulmonary symptoms. ${ }^{7}$

The patient's physical examination on April $18^{\text {th }}, 2018$, found a BMI of 14.95 $\mathrm{kg} / \mathrm{m}^{2}$ (underweight), enlarged right submandibular lymph node, $\pm 1 \mathrm{~cm}$ in diameter, felt solid and squishy. The patient's chest examination showed 2 lumps in the left superolateral chest, \pm 0.5 and $1 \mathrm{~cm}$ in diameter, and not fixed. Lung examination showed no abnormality. Chest X-rays on December $8^{\text {th }}, 2010$ up to April $14^{\text {th }}, 2018$, generally showed pictures of infected bronchiectasis and emphysematous lung. Ct-scan examination on July 19 $9^{\text {th }}, 2016$ and March $5^{\text {th }}, 2018$ found bilateral lung nodules in accordance with the metastatic process, bilateral pulmonary cystic bronchiectasis and right \& left axillary lymph nodes. Clinical manifestation of NTM is not specific, especially if bronchiectasis and COPD are present. Rhonchi, crackles, and wheezing were found on auscultation.

In patients with NTM caused by complex M. avium and bronchiectasis in post-menopausal women, many of them have similar symptoms such as thin body which could be accompanied by scoliosis, excavated pectus and mitral valve prolapse. $^{2}$ Radiological imaging of NTM could obtain: bronchiectasis, nodular lesions, cavity lesions and parenchymal consolidation ${ }^{8}$. CT-scan of a nodular bronchiectasis type could occur predominantly in non-smoking women, people of old age without previous pulmonary disease and generally appear in thin people. ${ }^{9}$

Microbiological examination on November $3^{\text {rd }}$, 2016 showed sputum AFB $1+$, TCM MTB Rif from July $7^{\text {th }}, 2015$ until October 30 ${ }^{\text {th }}$, 2017 showed MTB Not Detected. Sensitivity test on October $13^{\text {th }}$, 2012 showed bacteria resistant to Isoniazid \& Ethambutol and sensitive to Rifampin, Streptomycin, Kanamycin, Ofloxacin \& Amikacin. In LJ's media culture on December $27^{\text {th }}, 2018$, MTB had grown. August $9^{\text {th }}, 2011$ showed MOTT, July $14^{\text {th }}$, 2017 showed MTB, and May 18 ${ }^{\text {th }}, 2018$ showed NTM. The results of the molecular tests with Real Time PCR of the sputum on June $2^{\text {nd }}, 2018$ indicated strongly of NTM infection. In determining the diagnosis of NTM, at least three sputum samples are required, and incubated in one or more solid media and one liquid media. The quantity of colony growth (usually from 0 to $4+$ ) is essential to assess clinical significance and response to treatment. The LöwensteinJensen medium, although very good for growing Mycobacterium tuberculosis, has 
generally lower ability than Middlebrook solid media in the case of $M$. avium complex. In low and middle income countries, solid media is preferably used with Löwenstein Jensen's media. ${ }^{1}$ Acid Fast Bacteria staining could not differentiate MTB and NTM. ${ }^{10}$ Specific growth inhibitors such as nitrobenzoic acid (PNB), and nitro-alpha-acetylamino-beta-hydroxy propiophenone are able to inhibit complex mycobacterium tuberculosis and are useful for differentiating NTM. The role of the DST is to be a guide in drug regimen selection. However, DST in NTM is still difficult and controversial due to differences between in vitro and in vivo results, with the exception of macrolides and amikacin. ${ }^{11}$ Among SGM (Slow Growth Mycobacterium), there is a correlation between macrolides and amikacin in lung disease due to infection by Mycobacterium Avium Complex and Rifampicin by $M$. kansasii. ${ }^{2}$ Gene sequencing molecular test allows for higher discrimination. Targets selected for discriminatory determination: the hsp65 and rpoB and 16S-23S internal transcribed spacer (ITS) genes could identify down to the subspecies level, while the 16S Rrna sequencing gene allows discrimination to the species level for most species, or at least to the complex level, particularly for RGM. ( $\mathrm{M}$ fortuitum, $\mathrm{M}$ chelonae, $\mathrm{M}$ abscessus complex). ${ }^{12}$ In this case, gene sequencing still cannot be examined due to limited health facilities.

In other supporting examinations -the anatomical pathology examination on May $3^{\text {rd }}, 2008$ there was found an Infiltrating Ductal Cell Carcinoma Mammae, and Submandibular FNAB on November $10^{\text {th }}$, 2017 obtained a Metastatic Carcinoma with the impression of Mucinous Carcinoma. Mammography examinations on March $30^{\text {th }}, 2016$ and April 18 $8^{\text {th }}, 2018$ revealed multiple left solid mass and cystic breast mass accompanied by bilateral axillary lymphadenopathy. This patient was thus diagnosed with $\mathrm{Ca}$ mammae. The likelihood of NTM transmission affects patients who do not have AIDS but are immunosuppressed -e.g., neoplasia, who have received transplants, or who are on prolonged steroid treatment- and the organisms most frequently isolated are $\mathrm{M}$. avium complex and M.kansasii. M. avium complex causes fever of unknown origin, whereas M.kansasii generally causes subcutaneous nodules and abscesses that drain spontaneously. ${ }^{1}$

The patient in this case was given therapy: Rifampin, Levofloxacin, Ethambutol Doxycycline and Azithromycin with various doses. Treatment options for disease caused by NTM depend on three factors: the type of clinical presentation, the species of the NTM causing the disease and the patient's immune status. In vitro resistance towards the majority of antituberculosis drugs is one of the characteristics of this mycobacterium, which, until now, required the need for aggressive treatment of up to five or six drugs for a long period of time. ${ }^{1}$ Treatment for the disease induced by MAK: Macrolides (clarithromycin and azithromycin) are the cornerstone of treatment for MAK-induced lung disease. ${ }^{13}$ The standard regimen of choice includes: rifamycin (rifampin or rifabutin), 
ethambutol, and macrolides given for 18-24 months, and 12 months of negative sputum cultures. $^{2} \quad$ M.kansasii is sensitive to standard anti-TB drugs except for pyrazinamide, and there is a good correlation between in vitro and in vivo susceptibility, especially towards rifampin. ${ }^{11}$ Due to the excellent macrolide activity of M. kansasii, a regimen which contains the admission macrolide is also suggested. ${ }^{14}$

\section{Conclusion}

A case of 42-years old woman, with clinical symptoms of coughing up blood, shortness of breath, chest pain, fever, night sweats, decreased appetite and body weight was reported. From the physical examination, it was found that the right submandibular lymph node was enlarged $(+), \pm 1 \mathrm{~cm}$ in diameter, dense and supple. From the thoracic examination, there were 2 superolateral lumps in the left chest, \pm 0.5 $\mathrm{cm}$ and $1 \mathrm{~cm}$ in diameter, not fixed.

Radiological examination showed bronchiectasis, chest CT scan showed multiple nodules in bilateral lungs, suspected metastatic process dd infection, and bilateral, infected cystic bronchiectasis. Mammography showed multiple masses, solid and cystic, of the left breast. The microbiological examination of the sputum resulted in AFB 1+. TCM showed that MTB was not detected. And the initial culture of TB and the last culture showed NTM. The anatomical pathology examination showed Infiltrating Ductal Cell Carcinoma Mammae. The patient was later diagnosed with $\mathrm{Ca}$ Mammae Dextra Post Mastectomy Susp. Metaprocess to the Lungs with Pulmonary TB and NTM.

The patient then received chemotherapy for breastfeeding and category 1 antituberculosis drug regiment in 2009 and NTM treatment from 2012 to 2017, then returned to category 2 antituberculosis drug regiment treatment without Streptomycin injection from 2017 to 2018.Currently the patient showed symptoms that tend to persist, with the chief complaint being coughing up blood that is felt to come and $\mathrm{go}^{14}$.

\section{References}

1. Luna JAC. A tuberculosis guide for specialist physicians. International Union Against Tuberculosis and Lung Disease; 2004.

2. Griffith DE, Aksamit T, Brown-Elliott BA, Catanzaro A, Daley C, Gordin F, et al. An Official ATS/IDSA Statement: Diagnosis, Treatment, and Prevention of Nontuberculous Mycobacterial Diseases. Am J Respir Crit Care Med [Internet]. 2007 Feb 15;175':367-416. Available from:

http://www.atsjournals.org/doi/abs/10.11 64/rccm.200604-571ST

3. Kendall B, Winthrop K. Update on the Epidemiology of Pulmonary Nontuberculous Mycobacterial Infections. Semin Respir Crit Care Med [Internet]. 2013 Mar 4;34(01):087-94. Available from: http://www.thiemeconnect.de/DOI/DOI?10.1055/s-00331333567 
4. Adjemian J, Olivier KN, Seitz AE, Holland SM, Prevots DR. Prevalence of Nontuberculous Mycobacterial Lung Disease in U.S. Medicare Beneficiaries. Am J Respir Crit Care Med [Internet]. 2012 Apr 15;185':881-6. Available from:

http://www.atsjournals.org/doi/abs/10.11 64/rccm.201111-2016OC

5. Honda JR, Knight V, Chan ED. Pathogenesis and Risk Factors for Nontuberculous Mycobacterial Lung Disease. Clin Chest Med [Internet]. 2015 Mar;36 1 :1-11. Available from: https://linkinghub.elsevier.com/retrieve/ pii/S027252311400104X

6. Kwon YS, Koh W-J. Diagnosis of Pulmonary Tuberculosis and Nontuberculous Mycobacterial Lung Disease in Korea. Tuberc Respir Dis (Seoul) [Internet]. 2014;77¹: 1 . Available from: http://etrd.org/journal/view.php?doi=10.4046/tr d.2014.77.1.1

7. Huitt GA, Daley CL. Clinic in chest medicine. Nontuberculous mycobacteria. Elsevier. 2015;36 ${ }^{1}: 125$.

8. Jeong YJ, Lee KS, Koh W-J, Han J, Kim TS, Kwon OJ. Nontuberculous Mycobacterial Pulmonary Infection in Immunocompetent Patients: Comparison of Thin-Section CT and Histopathologic Findings. Radiology [Internet]. 2004 Jun;2313:880-6. Available from: http://pubs.rsna.org/doi/10.1148/radiol.2 313030833

9. Kartalija M, Ovrutsky AR, Bryan CL, Pott GB, Fantuzzi G, Thomas J, et al. Patients with Nontuberculous Mycobacterial Lung Disease Exhibit Unique Body and Immune Phenotypes. Am J Respir Crit Care Med [Internet]. 2013 Jan 15;187²:197-205. Available from:

http://www.atsjournals.org/doi/abs/10.11 64/rccm.201206-1035OC

10. Maurya A, Nag V, Kant S, Sharma A, Gadepalli R, Kushwaha RS. Recent methods for diagnosis of nontuberculous mycobacteria infections: Relevance in clinical practice. Biomed Biotechnol Res J [Internet]. 2017; $1^{1}: 14$. Available from: http://www.bmbtrj.org/text.asp?2017/1/1 /14/211406
11. Van Ingen J. Microbiological Diagnosis of Nontuberculous Mycobacterial Pulmonary Disease. Clin Chest Med [Internet]. $2015 \quad$ Mar;36 $143-54$. Available from: https://linkinghub.elsevier.com/retrieve/ pii/S0272523114001130

12. De Zwaan R, van Ingen J, van Soolingen D. Utility of rpoB Gene Sequencing for Identification of Nontuberculous Mycobacteria in the Netherlands. J Clin Microbiol [Internet]. 2014 Jul $1 ; 52^{7}: 2544-51$. Available from: https://jcm.asm.org/content/52/7/2544

13. Egelund EF, Fennelly KP, Peloquin CA. Medications and Monitoring in Nontuberculous Mycobacteria Infections. Clin Chest Med [Internet]. 2015 Mar;36 ${ }^{1}: 55-66$. Available from: https://linkinghub.elsevier.com/retrieve/ pii/S0272523114001099

14. Kasperbauer SH, De Groote MA. The Treatment of Rapidly Growing Mycobacterial Infections. Clin Chest Med [Internet]. 2015 Mar;36 ${ }^{1}: 67-78$. Available from: https://linkinghub.elsevier.com/retrieve/ pii/S0272523114001075 